Archiv für Mikrobiologie, Bd.29, S.38—50 (1958)

(Department of Botany, University of Michigan, Ann Arbor, Mich.)

\title{
Physiology of the Cell Surface of Neurospora Ascospores
}

\author{
Entranee of anions and non-polar compounds*
}

\author{
By \\ A. Sussman, R. Holton and Berta von Böventer-Heidenhayn \\ With 8 Figures in the Text
}

(Eingegangen am 23. September 1957)

In connection with studies of dormancy in ascospores of Neuraspora tetrasperma, the changes in their permeability after activation have been investigated. In a previous publication (LowRY etal. 1957), the adsorption of cations to the cell surface has been described. The penetration of cations, as judged by their effect upon respiration and germination, did not occur until almost two hours after activation. This was true for inorganic cations like $\mathrm{Ag}^{+}, \mathrm{UO}_{2}^{++}$and $\mathrm{Cu}^{++}$as well as for organic ones like polymyxin-B. These materials were excluded from those sites within the cell which were sensitive to them and were only adsorbed just before the first visible signs of germination could be detected. Support for these conclusions derives also from studies of the electrophoretic mobility of these cells wherein it has been shown that they possess a strong negative charge (LowRY and StSSMan, unpublished). The work to be reported below was undertaken in order to supplement the data on the uptake of cations with information concerning the penetration of anions and of certain non-polar compounds.

\section{Materials and Methods}

Ascospores were obtained largely as described by GoDDARD (1935); however, strains $37 \% .4$ and $37 \% .5$ were crossed and grown at $27^{\circ} \mathrm{C}$. After being harvested, the ascospores were stored in as cold-room at $4^{\circ} \mathrm{C}$. Activation was usually accomplished by heating at $58^{\circ} \mathrm{C}$ for 10 to 20 minutes in a thermostated water bath. Such techniques as the estimation of ascospore concentration, incubation of spores after activation, and the procedures used in counting the percentage germination were as described in SUSSMAN (1954). Unless otherwise noted, a final concentration of $0.5 \mathrm{mg}$. of ascospores per ml. was used.

Respirometric measurements were performed as described by UMBREIT, BURRIs and Stauffer (1949). In general a total of $1.2 \mathrm{ml}$. of fluid was used in Warburg vessels of approximately $7 \mathrm{ml}$. capacity. Into each vessel $0.9 \mathrm{ml}$ of distilled water were pipetted, and then either $2.0 \mathrm{mg}$. of activated or $9.0 \mathrm{mg}$. of dormant ascospores

* This work was made possible by a grant from the Michigan-Memorial Phoenix Project of the University of Michigan to whom the authors would like to express their gratitude. 
were added; $0.1 \mathrm{ml}$. of the substance to be tipped were added from the sidearm. The $20 \%$ (w/v) $\mathrm{KOH}$ used as an absorbent for $\mathrm{CO}_{2}$ comprised the rest of the volume and was added to the well in the main compartment of the vessel. In the experiments, wherein anaerobic conditions were imposed, a gas mixture of $95 \%$ nitrogen and $5 \% \mathrm{CO}_{2}$ was used. This mixture was freed of oxygen by being passed over hot reduced copper turnings before use.

The chemicals used in these experiments were of reagent grade. Sodium fluoroacetate, obtained through the courtesy of Dr. Theodore Brody, Department of Pharmacology, University of Michigan, was recrystallized twice from alcohol before being used. Monochloroacetic and dichloroacetic acid were obtained through the courtesy of Kay-Fries Chemicals, Inc., New York 16, N.Y. The 5-nitro-2-furfuryl methyl ether used in these experiments was obtained through the cooperation of Dr. John Yurchenko of the Eaton Laboratories, Norwich, N.Y.

Fluoride was analyzed by the method of Hunter, MaCNuLty and TerRy (1953), wherein the bleaching of an aluminium-hematoxylin lake was studied spectrophotometrically at $570 \mu$.

$\mathrm{P}^{32}$ determinations were made by means of an end window counter and scaler, and enough counts were made to assure less than $2 \%$ counting error. The aluminium planchets contained $0.3 \mathrm{ml}$ of the dried sample. Phosphorus concentrations were determined by the method of Frske and Subsarow (1925).

\section{Results}

The effect of various anions upon the germination of ascospores of $N$. tetrasperma was studied by mixing $1 \mathrm{ml}$. of a suspension containing $1 \mathrm{mg}$. of spores per ml. with an equal volume of various concentrations of the anion to be tested. Incubation of the spores and the determination of the percentage germination were done in the usual way; the results are outlined in Table 1 . The data show the toxicity of cyanide, azide, fluoride, cysteine und dichloroacetic acid, which are effective at concentrations greater than $1 \cdot 10^{-4} \mathrm{~m}$. The rest of the substances used are about one-tenth as effective as these.

That cations are adsorbed on the surface of dormant ascospores and do not gain access to sensitive sites in the cell until germination occurs has been shown by LowRy et al. (1957). To test the effect of anions, a suspension of dormant ascospores was mixed with an equal volume of various concentrations of the toxic anions used in the experiment described above. In order to insure that no dissociation occured, the solutions of the poisons were made up in $0.1 \mathrm{n}$ $\mathrm{HCl}$ and the ascospores were exposed to these substances for varying periods of time. (It had previously been determined that dormant cells are not affected by incubation in $0.05 \mathrm{n} \mathrm{HCl}$, which was the final concentration in the mixtures after the ascospores had been added.) Thereupon, the spores were washed free of the poisons by 4 rinses of distilled water, activated, incubated, and the percentage germination determined as before. The data in Table 2 disclose that in all cases more poison is needed to prevent germination of the dormant than of the activated spores. 
Some insight into the kinetics of fluoride inhibition was sought by exposing dormant ascospores to various concentrations of this substance for varying intervals of time. In order to remove the residual fluoride, the spores were rinsed in 3 changes of destilled water, after which they were activated and incubated. Table 3 provides the results, which indicate that, when $1 \cdot 10^{-2} \mathrm{~m}$ is used, enough of the poison is taken up in $10 \mathrm{mi}$ nutes to insure complete toxicity. On the other hand, when $1 \cdot 10^{-3} \mathrm{~m}$ is used, an hour or more is required in order to achieve the same amount of toxicity.

Table 1. Toxicity of anions after continual incubation with activated ascospores of $N$. tetrasperma

The poisons were dissolved in water and mixed with the spores after activation

\begin{tabular}{|c|c|c|c|c|c|}
\hline Substance & $\begin{array}{c}\text { concentr. } \\
\text { (molar) }\end{array}$ & $\begin{array}{l}\text { percent. } \\
\text { germin. }\end{array}$ & Substance & $\begin{array}{c}\text { concentr. } \\
\text { (molar) }\end{array}$ & $\begin{array}{l}\text { percent. } \\
\text { germin. }\end{array}$ \\
\hline \multirow[t]{3}{*}{ sodium azide } & $1 \cdot 10^{-3}$ & 0 & \multirow[t]{2}{*}{ acetic acid } & $1 \cdot 10^{-2}$ & 0 \\
\hline & $1 \cdot 10^{-4}$ & 78 & & $1 \cdot 10^{-3}$ & 84 \\
\hline & $1 \cdot 10^{-5}$ & 90 & \multirow[t]{3}{*}{ sodium arsenite } & $1 \cdot 10^{-2}$ & 0 \\
\hline \multirow{5}{*}{$\begin{array}{l}\text { sodium fluoride } \\
\text { sodium } \\
\text { fluoroacetate } \\
\text { formic acid }\end{array}$} & $1 \cdot 10^{-2}$ & 0 & & $1 \cdot 10^{-3}$ & 49 \\
\hline & & & & $1 \cdot 10^{-4}$ & 90 \\
\hline & $1 \cdot 10^{-2}$ & 0 & \multirow[t]{2}{*}{ propionic acid } & $1 \cdot 10^{-2}$ & 0 \\
\hline & $1 \cdot 10^{-2}$ & 0 & & $1 \cdot 10^{-3}$ & 94 \\
\hline & $1 \cdot 10^{-3}$ & 86 & \multirow[t]{2}{*}{ butyric acid } & $1 \cdot 10^{-2}$ & 0 \\
\hline \multirow[t]{2}{*}{ formaldehyde } & $1 \cdot 10^{-2}$ & $80^{x}$ & & $1 \cdot 10^{-3}$ & 93 \\
\hline & $1 \cdot 10^{-3}$ & 93 & \multirow[t]{2}{*}{ l-cysteine } & \multirow[t]{2}{*}{$1 \cdot 10^{-3}$} & \multirow[t]{2}{*}{0} \\
\hline \multirow{2}{*}{$\begin{array}{l}\text { monochloroacetic } \\
\text { acid }\end{array}$} & $1 \cdot 10^{-2}$ & 0 & & & \\
\hline & $1 \cdot 10^{-3}$ & 94 & potassiurn & $1 \cdot 10^{-2}$ & 0 \\
\hline \multirow{2}{*}{$\begin{array}{l}\text { dichloroacetic } \\
\text { acid }\end{array}$} & $1 \cdot 10^{-2}$ & 0 & \multirow[t]{2}{*}{ oyanide } & $1 \cdot 10^{-3}$ & $66^{1}$ \\
\hline & $1 \cdot 10^{-3}$ & 0 & & $1 \cdot 10^{-4}$ & 94 \\
\hline
\end{tabular}

${ }^{1}$ Germ buds only, no germ tubes formed.

This experiment was repeated with sodium azide and sodium fluoroacetate in $0.1 \mathrm{n} . \mathrm{HCl}$; the results (Table 4) suggest that these substances penetrate the dormant ascospores more slowly than does fluoride.

Superficially, at least, the results obtained with fluoride and other toxic anions resemble those reported with cations. That is, the toxicity of the anions was much greater when activated cells were continually incubated in the substances than when only dormant cells were treated. It was therefore of interest to consider the possibility that anions, like cations, are bound to the surface of the ascospores.

One approach to this question was to attempt to remove the toxicity by eluting the anion. If these materials were bound to the surface of the cell, such elution should have been feasible. Consequently, ascospores were incubated in acidified $1 \cdot 10^{-2} \mathrm{~m}$ sodium fluoride for 30 minutes and 
afterwards washed free of fluoride and resuspended in $0.1 \mathrm{~m}$ solutions of various halogen salts for 30 minutes. These were removed as before, and the spores were activated and incubated. In no case, including potassium iodide, potassium bromide, potassium chloride, calcium chloride, did any of the halogens remove the effect of fluoride.

Table 2. Effect of treatment of dormant ascospores of $N$. tetrasperma with acids, prior to activation

The experiments were performed in $0.05 \mathrm{n} \mathrm{HCl}$ and the final $\mathrm{p}_{\mathrm{H}}$ was between 1.5 and 2.0 unless otherwise noted. After being incubated for the stated time the spores were washed free of the poison, activated, and the percentage germination determined

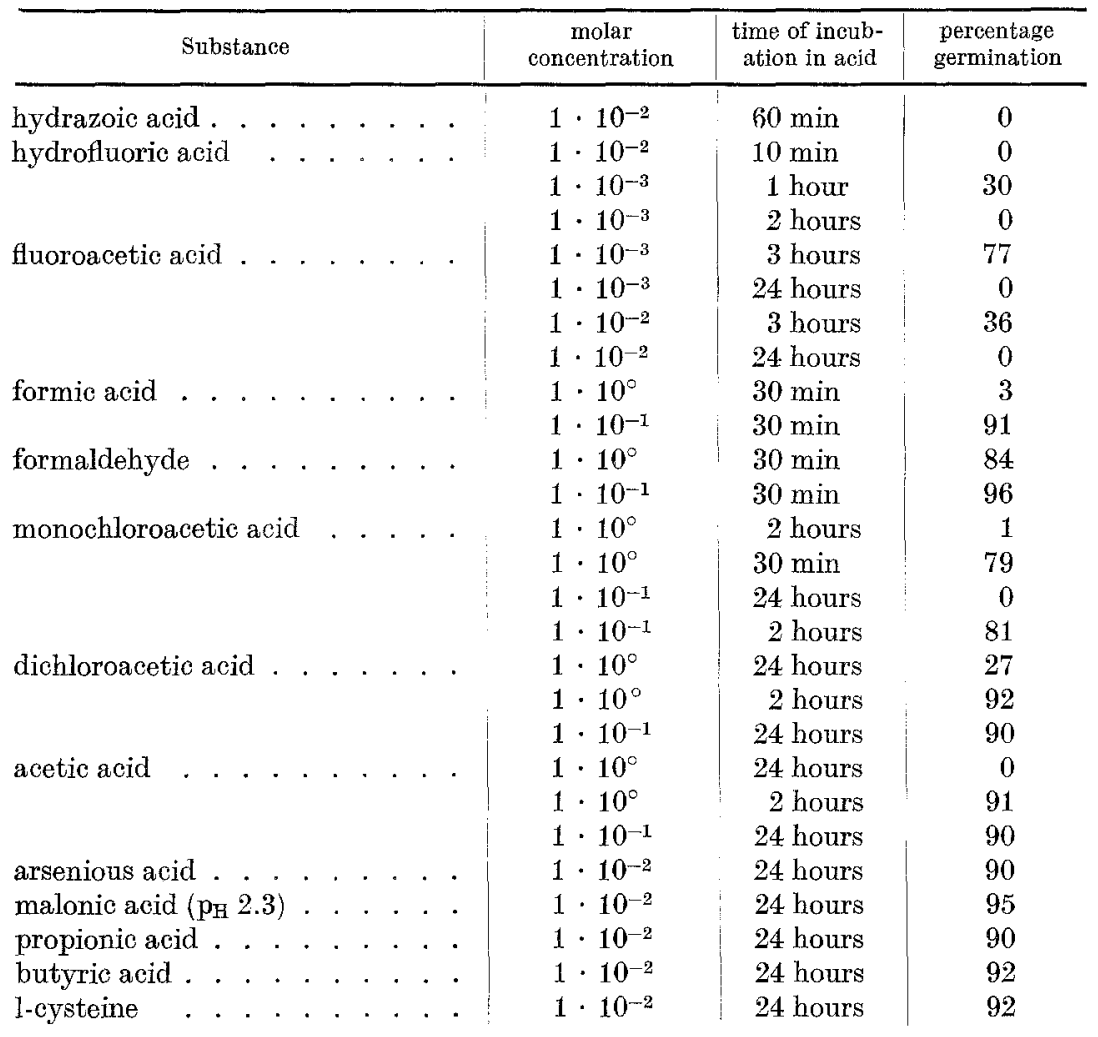

Influence of $\mathrm{p}_{\mathbf{H}}$. It had been noted in previous experiments that the $p_{H}$ had a marked influence upon the toxicity of acetate (SUSSMAN 1954) toward ascospores of $N$. tetrasperma. In order to determine whether such an effect was general for anions, experiments were carried out with fluoride wherein the $\mathrm{p}_{\mathrm{H}}$ of $2 \cdot 10^{-2} \mathrm{~m}$ and $2 \cdot 10^{-3} \mathrm{~m}$ solutions was varied by the use of $\mathrm{NaOH}$. Equal volumes of these solutions and of dormant 
Table 3. Effect of fuoride upon the germination of ascospores of $N$. tetrasperma A final concentration of $0.5 \mathrm{mg}$. of ascospores per $\mathrm{ml}$. was incubated for various times with sodium fluoride. The residual fluoride was removed by 3 rinses in distilled water, after which the ascospores were activated and incubated in distilled water. All solutions of the poison were made up in $0.1 \mathrm{n} \mathrm{HCl}$, and controls were run in the same concentration of acid without the poison

\begin{tabular}{c|c|c|c|c}
\hline \multirow{2}{*}{$\begin{array}{c}\text { Time of incubation } \\
\text { in poison } \\
\text { (minutes) }\end{array}$} & \multicolumn{3}{|c|}{ percentage germination in the following concentrations of NaF } \\
\cline { 2 - 5 } & $1 \cdot 10^{-2} \mathrm{~m}$ & $1 \cdot 10^{-3} \mathrm{~m}$ & $1 \cdot 10^{-4} \mathrm{~m}$ & control \\
\hline 10 & 0 & 96 & 96 & 95 \\
20 & 0 & 85 & 95 & 95 \\
30 & 0 & 51 & 95 & 90 \\
60 & 0 & 3 & 94 & 92 \\
10 & 0 & & & \\
20 & 0 & 94 & 99 & 86 \\
30 & 0 & 67 & 87 & 94 \\
60 & 0 & 6 & 93 & 91 \\
120 & 0 & 1 & 95 & 93 \\
& & & & 95
\end{tabular}

Table 4. Effect of fluoroacetic acid and hydrazoic acid upon germination of ascospores of Neurospora tetrasperma

A final concentration of $0.5 \mathrm{mg}$. of ascospores per $\mathrm{ml}$. was incubated for various times in several concentrations of each inhibitor. The residuum was removed by 3 rinses in distilled water, after which the ascospores were activated and incubated in distilled water. All solutions of the poisons were made up in $0.1 \mathrm{n} \mathrm{HCl}$, and controls were run in the same concentration of acid without the poison

\begin{tabular}{c|c|c|c|c}
\hline \multirow{2}{*}{$\begin{array}{c}\text { Time of incubation } \\
\text { in poison } \\
\text { (minutes) }\end{array}$} & \multicolumn{4}{|c}{ percentage germination } \\
\cline { 2 - 5 } Fluoroacetic acid & $1 \cdot 10^{-2} \mathrm{~m}$ & $1 \cdot 10^{-3} \mathrm{~m}$ & $1 \cdot 10^{-4} \mathrm{~m}$ & control \\
10 & & & & \\
20 & 78 & 91 & 83 & 97 \\
30 & 76 & 93 & 92 & 93 \\
60 & 69 & 89 & 90 & 90 \\
120 & 26 & 87 & 93 & 95 \\
180 & 8 & 85 & 95 & 95 \\
Hydrazoic acid & 3 & 77 & 91 & 90 \\
10 & & & & \\
20 & 92 & 97 & 95 & 96 \\
30 & 97 & 95 & 92 & 95 \\
60 & 60 & 95 & 93 & 95 \\
120 & 0 & 95 & 97 & 94 \\
& 0 & 88 & 96 & 97
\end{tabular}

ascospores ( $1 \mathrm{mg}$. per $\mathrm{ml}$.) were mixed, activated, and the percentage germination determined. The results are plotted in Fig. 1. The data show that the lower the $\mathrm{p}_{\mathrm{H}}$, the greater the effect of fluoride; a variation of only about 0.5 of a $\mathrm{p}_{\mathrm{H}}$ unit spells the difference between complete toxicity and no effect. 
A similar experiment was performed with azide, in which the $\mathrm{p}_{\mathrm{H}}$ was poised by either phosphate or Macllwain's buffer system. The data in Table 5 disclose that, as in the case of fluoride, the toxicity of azide varies inversely with the $p_{H}$. Furthermore, this effect does not seem to be related to the type of buffer used, for the results were identical whether phosphate or MacIlwain's buffer was used.

Activated ascospores respond in the same way to the addition of fluoroacetate. In this experiment, the $\mathrm{p}_{\mathbf{H}}$ of the solution containing $2 \cdot 10^{-2} \mathrm{~m}$ fluoroacetate was altered by the addition of $\mathrm{HCl}$, and equal parts of this and an activated spore suspension were mixed. Incubation was continued at $20^{\circ} \mathrm{C}$ for 3 hours, after which the percentage germination was determined.

It was at

$$
\begin{array}{ccccccc}
\mathrm{pH} & 3.0 & 3.5 & 4.0 & 4.5 & 5.0 & 5.5 \\
\% & 0 & 52 & 86 & 91 & 90 & 90
\end{array}
$$

Uptake of anions. Another means of comparing anion and cation uptake was by a study of the kinetics of the process. This was attempted

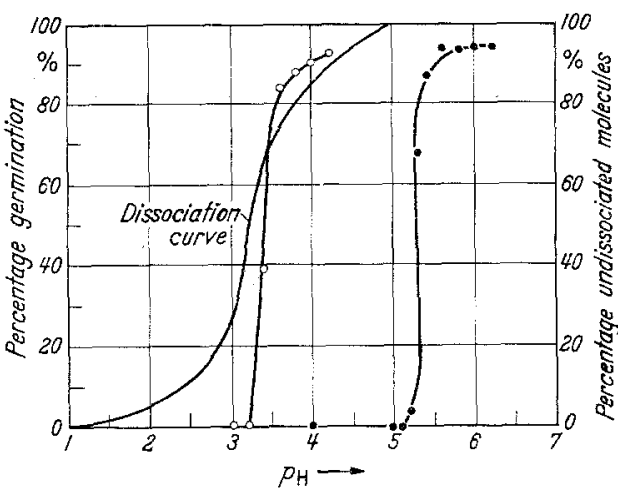

Fig. 1. Effect of $\mathrm{p}_{\mathrm{H}}$ upon the toxicity of fluoride to ascospores of $N$. tetrasperma. The fluoride was added before activation. Results are given as the average of two determinations. Open circles: $1 \cdot 10^{-3} \mathrm{~m}$; filled circles: $1 \cdot 10^{-2} \mathrm{~m}$ by the use of $\mathrm{P}^{32}$, to which $10 \mathrm{mg}$. of ascospores per $\mathrm{ml}$. were exposed for varying periods of time. The total phosphorus concentration in the incubation mixture was $0.25 \mu \mathrm{g}$. per $\mathrm{ml}$., and the solution was at $\mathrm{p}_{\mathrm{H}} 1.5$. Incubation was carried

Table 5. Influence of $p_{\mathrm{H}}$ on the toxicity of azide to dormant ascospores of $N$. tetrasperma A final concentration of $1 \cdot 10^{-2} \mathrm{~m}$ azide was used with a spore suspension of $1 \mathrm{mg}$. per $\mathrm{ml}$. Incubation in azide was continued for 30 minutes before the ascospores were washed and activated. The buffer concentration was $0.1 \mathrm{~m}$ except in the case of Macllwain's buffer wherein $0.5 \cdot 10^{-2} \mathrm{~m} \mathrm{Na}_{2} \mathrm{HPO}_{4}$ and $0.25 \cdot 10^{-2} \mathrm{~m}$ citrate were mixed. The germination of controls was unaffected by incubation in the buffers alone

\begin{tabular}{c|l|c|c|c|c}
\hline$p_{\text {H }}$ & Buffer & $\begin{array}{c}\text { percentage } \\
\text { germination }\end{array}$ & $\mathrm{p}_{\mathrm{H}}$ & Buffer & $\begin{array}{c}\text { percentage } \\
\text { germination }\end{array}$ \\
\hline 1,0 & HCl & 0 & 3.0 & MacIlwain's & 0 \\
$\mathbf{2 . 0}$ & phosphate & 0 & 4.0 & MacIlwain's & 0 \\
$\mathbf{3 . 0}$ & phosphate & 0 & 4.5 & MacIlwain's & 22 \\
4.0 & phosphate & 0 & 5.0 & MacIlwain's & 96 \\
5.0 & phosphate & 95 & 6.0 & MacIlwain's & 96 \\
6.0 & phosphate & 98 & & &
\end{tabular}


out in $125 \mathrm{ml}$. Erlenmeyer flasks containing $20 \mathrm{ml}$. of spore suspension on a reciprocal shaking machine at $20^{\circ} \mathrm{C}$. Aliquotes were withdrawn periodically and were plated and counted as described previously, with the results shown in Table 6. It seems reasonably certain that no significant uptake occurred under these conditions. This experiment was repeated at $\mathrm{p}_{\mathrm{H}} 2.0$ and 6.0 with the same results.

Table 6. $P^{32}$ uptake by dormant ascospores of $N$. tetrasperma

Ascospores (10 mg. per ml.) were incubated with $0.25 \mu \mathrm{g}$. per $\mathrm{ml}$. of phosphate solution at $\mathrm{p}_{\mathrm{H}}$ 1.5. Aliquots were removed at intervals, plated, and counted as described in the text. Results are the average of samples in triplicate except for the control which was run in sextuplicate

\begin{tabular}{c|c|c|c}
\hline Time in phosphate & counts per minute & Time in phosphate & counts per minute \\
\hline control (0 time) & $3011 \pm 74$ & 3 hours & $2938 \pm 51$ \\
$30 \mathrm{~min}$ & $3047 \pm 36$ & 7 hours & $2997 \pm 87$ \\
$60 \mathrm{~min}$ & $2987 \pm 79$ & 11 hours & $3036 \pm 23$ \\
& & 24 hours & $3005 \pm 55$
\end{tabular}

Fluoride uptake was also studied by mixing $20 \mathrm{ml}$. of a spore suspension containing $44 \mathrm{mg}$. of dormant ascospores per $\mathrm{ml}$. with an equal volume of $60 \mu \mathrm{g}$. of sodium fluoride per ml. dissolved in $0.1 \mathrm{n} \mathrm{HCl}$. This suspension was incubated and shaked at $20^{\circ} \mathrm{C}$. Aliquots were withdrawn at intervals,

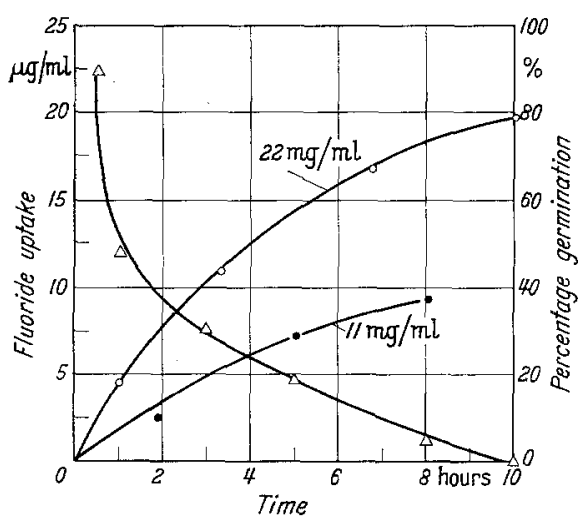

Fig. 2. Uptake of fluoride and its effect upon the germination of ascospores of $N$. tetrasperma. Germination results were obtained from an experiment utilizing $11 \mathrm{mg}$. of ascospores per $\mathrm{ml}$. Triangles: effect upon germination; circles: uptake of fluoride gas exchange. For this purpose, heat-activated ascospores were incubated in $1 \cdot 10^{-2} \mathrm{~m}$ sodium azide $\left(\mathrm{p}_{\mathrm{H}} 5.2\right)$, and their oxygen uptake was compared with that of untreated spores suspended in water. The results as shown in Fig. 3 disclose that azide almost completely prevents the respiratory 
increase attendant upon activation. Dormant cells were incubated in the same concentration of the poison and were washed in 3 changes of distilled water after 1 hour. The spores were activated as before, and their oxygen uptake was determined in the presence and absence of $\mathrm{Ca}^{++}$. It can be seen in Fig. 4 that the effect is almost the same as when activated cells are incubated continuously in the poison. Furthermore, in contrast to the case of toxic cations (Lowry et al. 1957), the effect of azide is not inhibited by $\mathrm{Ca}^{++}$.

These results were substantiated by experiments with fluoroacetate; dormant ascospores were exposed to the poison for 2 and 24 hours. The residual fluoroacetate was removed, and the ascospores were heat-activated after resuspension in water. Respiratory determinations were made, with the results shown in Fig. 5. As in the case of cells treated with azide, those exposed to fluoroacetate for 24 hours showed no increase in oxygen uptake due to activation. Although a smaller effect was noted when the ascospores were exposed to the poison for 2 hours, the inhibition was marked and not reversed by $\mathrm{Ca}^{++}$. It should be noted that

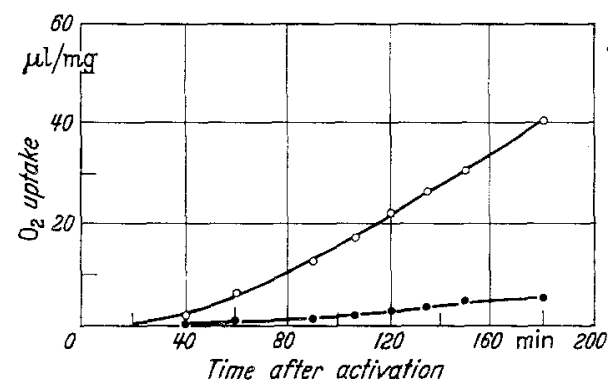

Fig. 3. Effect of sodium azide ( $\mathrm{p}_{\mathrm{H}}$ 5.2) upon oxygen uptake when continually incubated with activated ascospores of $N$. tetrasperma. A final concentration of $1 \cdot 10^{-2} \mathrm{~m}$ sodium azide was used with about $4.0 \mathrm{mg}$. of spores per vessel. Points represent the average of 5 determinations. Open circles: control $92 \%$ germination; filled circles: treated, no germination

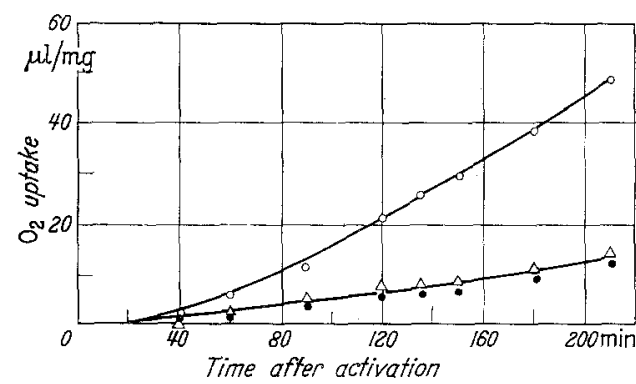

Fig. 4. Effect of sodium azide upon $\mathrm{O}_{2}$ uptake when dormant ascopores ( $5.0 \mathrm{mg}$. per vessel) were exposed to $1 \cdot 10^{-2} \mathrm{~m}$ (in $0.1 \mathrm{n} \mathrm{HCl}$ ) for 1 hour and then washed free of the poison and activated. Points represent the average of 5 determinations. Open circles: control, $87 \%$ germination; fllled eircles: treated, no germination; triangles: treated with $1 \cdot 10^{-2} \mathrm{~m} \mathrm{Ca}^{++}$, no germination the percentage germination was lower in the presence of this cation than in its absence, despite the similarity in respiratory rate. No explanation can be furnished for this effect at present.

A series of furfural analogues have been studied for their effect upon the activation process (Sussman 1953). One of the most toxic of these was 5-nitro-2-furfuryl methyl ether, whose effect upon the respiratory metabolism of ascospores was studied as above. As can be seen in Fig. 6, the inhibition of oxygen uptake does not occur until at least 60 minutes 
after activation, despite the fact that germination was sharply curtailed, as in the case of cells treated with azide or other acid poisons.

Since further work with intact ascospores required some knowledge of the effect of possible substrates, $0.11 \mathrm{~m}$ glucose was added, and the carbon

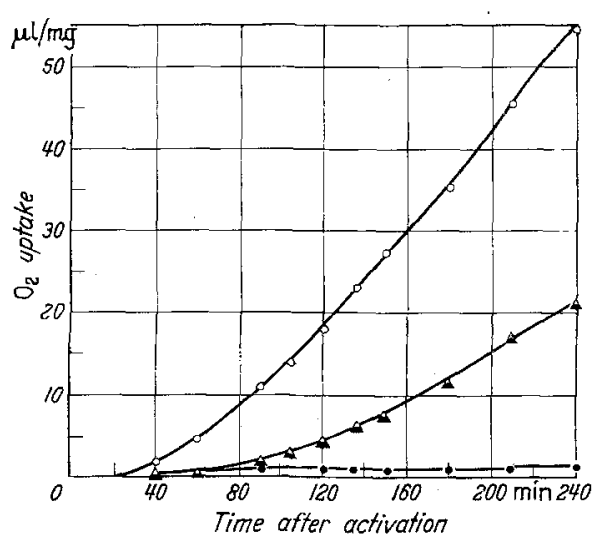

Fig. 5. Effect of sodium fluoroacetate upon $0_{2}$ uptake when dormant ascopores (4.5 mg. per vessel) 24 hours and then washed free of the poison and activated. Points represent the average of duplicate vessels. Open cireles: control, $91 \%$ germination; filled circles: treated 24 hours, no germination; open triangles: treated 2 hours, $24 \%$ germination; filled triangles: treated 2 hours plus $1 \cdot 10^{-2} \mathrm{~m} \mathrm{Ca}++$

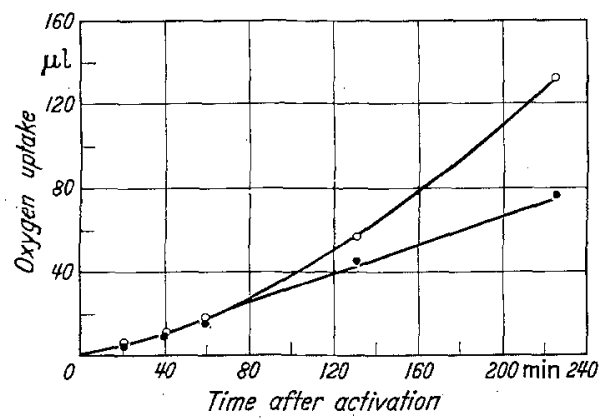

Fig. 6. Effect of 5-nitro-2-furfuryl methyl ether upon $\mathrm{O}_{2}$ uptake when continually incubated with activated ascospores of $N$. tetrasperma. A final concentration of $1 \cdot 10^{-2}$ in of the poison was used with approximately $2.0 \mathrm{mg}$. of aseospores per vessel. Points represent the average of duplicate samples. Open circles: control, $90 \%$ germination; filled circles: treated, no germination were exposed to $1 \cdot 10^{-2} \mathrm{~m}$ (in $0.1 \mathrm{n} \mathrm{HCl}$ ) for 2 and

dioxide output and the oxygen uptake of activated ascospores were measured. The data in Fig. 7 demonstrate that there is no effect upon gas exchange until $140 \mathrm{mi}$ nutes after activation. At this time the rate of both carbon dioxide evolution and oxygen uptake increased markedly, and because the respiratory quotient (R.Q.) was 1.0 it was assumed that the substrate was fully oxidized.

The gas exchange of dormant ascospores was the same in the presence and in the absence of the same amount of glucose.

It had been noted by GODDARD (1935) that anaerobically incubated ascospores evolved more $\mathrm{CO}_{2}$ than dormant cells for about an hour after activation, but thereafter they evolved comparatively less. In order to discover whether this decline was due to lack of substrate, and to investigate whether exogenous glucose could be used anaerobically, the following experiment was performed. Ascospores wereactivated and immediately placed in Warburg vessels in an atmosphere of $95 \%$ nitrogen and $5 \% \mathrm{CO}_{2}$. Thereupon, the amount of $\mathrm{CO}_{2}$ evolved by cells in the presence and absence of $0.11 \mathrm{~m}$ glucose was measured. The results are plotted in Fig. 8 . No significant difference in either oxygen uptake or $\mathrm{CO}_{2}$ output could be detected, and in no case did anaerobically incubated ascospores germinate. 


\section{Discussion}

When dormant ascospores of $N$. tetrasperma are incubated in adequate concentrations of different acids, germination is prevented even if the spores are washed and incubated in distilled water. However, the concentration necessary to poison the dormant ascospores was usually 100-fold higher than when the activated cells were incubated continuously in the acid. Furthermore, dormant spores were resistent to an incubation in toxic compounds like propionate for 24 hours, whereas activated spores were completely poisoned within the time necessary for the protrusion of the germ tube (3 hours at $20^{\circ} \mathrm{C}$ ). It was also found that dormant cells could be incubated in $0.05 \mathrm{n}$ acid so that much higher concentrations of the undissociated molecule could be obtained than was possible for activated cells which were restricted to a $\mathrm{p}_{\mathrm{H}}$ range between 3.0 and 8.0 .

That anionic substances penetrate more readily at an acid $p_{H}$ is amply demonstrated in Table 5 and Fig. 1. It would appear that the

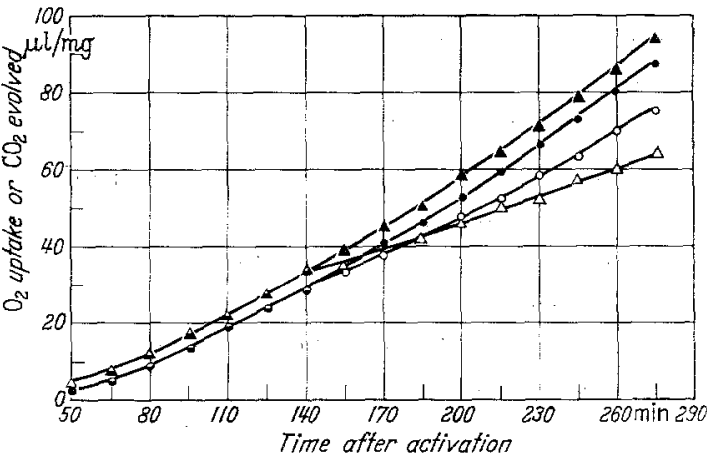

Fig. 7. The respiration of activated ascospores of $N$. tetrasperma in the presence and absence of glucose at a final concentration of $0.11 \mathrm{~m}$. Each vessel contained $1.2 \mathrm{mg}$. of ascospores and each point represents the average of triplicate samples. Open circles: $\mathrm{O}_{2}$ uptake of controls; filled circles: $\mathrm{O}_{2}$ uptake in presence of glucose; open triangles: $\mathrm{CO}_{2}$ evolution of controls; filled triangles: $\mathrm{CO}_{2}$ evolution in presence of glucose

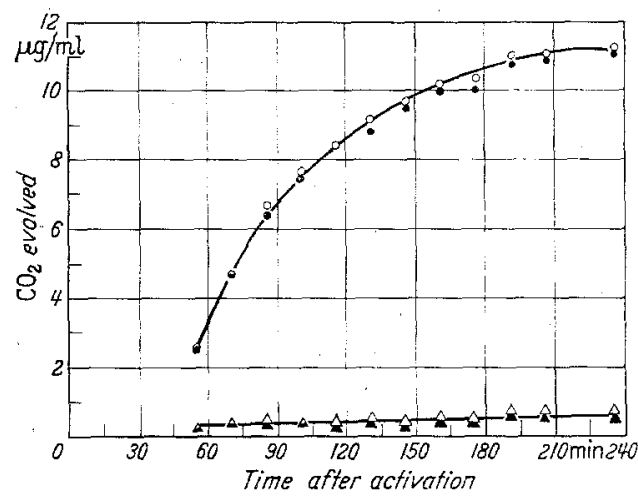

Fig. 8. Fermentative capacity of dormant and activated ascospores of $N$.tetrasperma in the presence and absence of glucose. Each vessel contained $9.2 \mathrm{mg}$. of dormant ascospores or $2.6 \mathrm{mg}$. of the activated ones. Each point represents the average of triplicate determination. Open circles: $\mathrm{CO}_{2}$ evolution of activated spores in presence of glucose; filled eircles: $\mathrm{CO}_{2}$ evolution of activated spores in absence of glucose; open triangles: $\mathrm{CO}_{2}$ evolution of dormant spores in presence of glucose; filled triangles: $\mathrm{CO}_{2}$ evolution of dormant spores in absence of glucose undissociated molecule must be in high concentration before fluoride (pK, 3.2) or azide $(\mathrm{pK}, 4.7)$ can penetrate the dormant cell. Similar results were obtained when fluoroacetate (pK, 2.7) was used with activated cells (Table 6). 
The curves in Fig. 1 are almost identical in shape with those found for the effect of fluoride on yeast respiration (SIMON and BEEvERs 1952). Although the resemblance between the dissociation curve and that for toxicity is close, their shapes are not identical; the latter can be displaced along the abscissa, depending upon the concentration of fluoride used. Several points of difference arise when these data on the penetration of anions are compared with the results of previous work with cations. These include the following:

1. All cations tested (Lowny et al. 1957) were adsorbed to the surface of Neurospora ascospores. The kinetics of uptake resemble those of the Freundlich isotherm, and these substances could be eluted by the use of other cations.

By contrast, the uptake of anions is linear with time, and their toxic effect is not inhibited by other anions. $\mathrm{PO}_{4} \equiv$ and probably other anions are not absorbed at all by dormant ascospores, whereas there was uptake of all cations tested.

2. The effect of cations upon the respiration of activated ascospores is never manifest until at least 90 minutes after activation (LowRY et al. 1957). This was used as evidence of the possibility that these substances, although removed from the solution by the cells, do not penetrate to sensitive loci until just before germination.

The same results were obtained when activated ascospores were incubated with anions like fluoroacetate, cysteine (Sussmas et al. 1956) and 5-nitro-2-furfuryl methyl ether (Fig. 6). However, when dormant cells were pre-treated with fluoroacetate for 24 hours, or with azide for 30 minutes, and then activated, very different results were obtained (Figs. 4 and 5). In these cases the rise in respiration associated with activation is obviously prevented from the start because these anions penetrate to sensitive sites almost at once. The data in Fig. 3 which were obtained when azide was added to activated cells corroborate these findings. Moreover, the effect of fluoride parallels that of azide almost exactly (unpublished results). EMERson (1954) has shown similar effects of azide upon ascospores of $N$. crassa, but for reasons as yet unexplained, furfural-activated spores were insensitive to this poison.

The conclusions drawn from these results are that acids of small size like hydrazoic and hydrofluoric penetrate the dormant and the activated ascospores with relative rapidity. On the other hand, larger ones like propionate, butyrate, cysteine, and phosphoric acids penetrate very slowly, or not at all. Fluoroacetate is intermediate in that it enters at a slow rate but rapidly enough to poison after 24 hours (Tables 2 and 4 ). Therefore, compounds which contain 2 carbon atoms approach the limit of size beyond which no penetration is effected, so that acetate and its 
analogues penetrate slowly and poison after 24 hours but propionate and larger compounds are innocuous even after this time. The delayed effect of cysteine and fluoroacetate upon the respiration of activated ascospores (Sussmar et al. 1956) can be explained as being due to their failure to penetrate until just before germination. This vitiates the use of these data to prove that a qualitatively different type of metabolism arises at the time of germination, although independent evidence still favors this conclusion. That the interpretation offered above is consistent with data on the size of the anions concerned is suggested by the fact that MoELLER (1952) gives $1.01 \AA$ as one dimension of the hydrazoic acid molecule which is of linear form. The other dimension is much longer (approx. $2.7 \AA$ ) but it is likely that the molecule can penetrate through its smaller dimension. On the other hand, $\mathrm{PO}_{4} \equiv$ is of tetrahedral form and is much larger than either the azide molecule in one of its dimensions or than fluoride in all of its dimensions (MoELLER 1952). These considerations would, therefore, seem to substantiate the interpretation proposed above.

\section{Summary}

Acids like hydrogen fluoride, hydrazoic and fluoroacetic have been shown to prevent the germination of ascospores of $N$. tetrasperma when dormant spores are treated. On the other hand, propionate, cysteine and others are ineffective when used in this way. When activated ascospores were treated, much lower concentrations of the acids were sufficient to poison the spores. As in other systems, these substances are most effective at a $\mathrm{pH}$ below their $\mathrm{pK}_{\mathrm{a}}$.

The kinetics of uptake of fluoride by dormant ascospores were studied and shown to be very different from those reported for cations. However, $\mathrm{P}^{32}$ was not absorbed by dormant ascospores, even at $\mathrm{p}_{\mathrm{HI}} \mathbf{1 . 5}$.

Respiratory inhibition by azide and fluoroacetate occurred immediately after the spores were activated, but in the case of 5-nitro-2-furfuryl methyl ether no effect was observed until just before germination occurred.

These results suggest that a permeability barrier exists in the dormant ascospore which disappears upon germination. Moreover, the dormant spore seems to be permeable to acids of small size but impermeable to those possessing more than 3 methylene groups or of equivalent size.

\section{Bibliography}

Emerson, Mary R.; Plant Physiol. 29, 418 (1954). - Flske, G. H., and Y. SubBarow: The colorimetric determination of phosphorus. J. of Biol. Chem. 66, 375-400 (1925). - GodDard, D. R.: J. of Gen. Physiol. 19, 45 (1935). -Hunter, G. J., B. J. MacNulty and E. A. TerRy: The determination of microgram quantities of fluoride. I. The use of the aluminum-haematoxylin complex. 
50 A. Sussman et al: Physiology of the Cell Surface of Neurospora Ascospores

Anal. Chim. Acta (Amsterd.) 8, 351-368 (19503). - Lowny, R. J., A. S. SUssmaN and Berta von Böventer-Hidentratn: Physiology of the cell surface of Neurospora ascospores. III. Distinction between the adsorptive and entrance phases of eation uptake. In Press. Mycologia (1957). - Moellur, T.: Inorganic Chemistry. An advanced textbook. New York: John Wiley and Sons, Inc. 1952. SIMON, E. W., and H. BeEvers: The effect of $p_{H}$ on the biological activities of weak acids and bases. I. The most usual relationship between $p_{H}$ and activity. New Phytologist 51, 163-190 (1952). - Sussman, A. S.: J. of Gen. Microbiol. 8, 211 (1953). - Sussman, A. S.: J. of Gen. Physiol. 38, 59 (1954). — Sussman, A. S., J. R, Distren and. J. Krakow: Metabolic aspects of Neurospora activation and germination. Plant Physiol. 31, 126--135 (1956), - Umbreit, W. W., R. H. BURRIS and J. F. STAUFFer: Manometric techniques and tissue metabolism. Minneapolis: Burgess Publ. Co. 1949. 